\title{
3D and 4D imaging of immune cells in vitro and in vivo
}

\author{
Cindy Nitschke • Alexandre Garin • \\ Marie Kosco-Vilbois • Matthias Gunzer
}

Accepted: 24 September 2008 / Published online: 15 October 2008

(C) Springer-Verlag 2008

\begin{abstract}
Analyzing the dynamics of cellular immune responses, although performed for decades in immunologic research, has seen an enormous increase in the number of studies using this approach since the development of intravital 2-photon microscopy. Meanwhile, new insights into the dynamics of cellular immunity are being published on a daily basis. This review gives a short overview of the currently most widely used techniques, both on the microscopy side as well as on the experimental part. Difficulties and promises will be discussed. Finally, a personal selection of the most interesting findings of the first 6 years of intravital 2-photon microscopy for immunological questions will be given. The overall aim is to get the reader interested into this fascinating way of investigating the immune response by means of "dynamic histology". This already has and will continue to broaden our view on how immune cells work in real life.
\end{abstract}

Keywords Cell migration - Intravital microscopy · 2-Photon microscopy $\cdot$ Germinal center

\section{Introduction}

The ability for autonomous migration is a critical function of immune cells (Gunzer 2007). All immune cells are

C. Nitschke $\cdot$ M. Gunzer $(\square)$

Institute of Molecular and Clinical Immunology,

Otto-von-Guericke University, Leipziger Str. 44,

39120 Magdeburg, Germany

e-mail: matthias.gunzer@med.ovgu.de

A. Garin · M. Kosco-Vilbois

NovImmune S.A., 14 ch. des Aulx,

1228 Plan-Les-Ouates, Geneva, Switzerland derived from hematopoietic stem cells (HSC) which reside in the bone marrow. HSC constantly produce offspring that generates mature effector cells like, e.g., in the case of granulocytes (PMN) (Geiger et al. 2007). Under normal circumstances, PMN stay resident in the bone marrow for a while and relatively low numbers are permanently released at a constant rate. However, they can be mobilized in dramatically increased numbers in danger situations, e.g. during a peripheral infection or inflammation (De et al. 2008; Wengner et al. 2008). In contrast, lymphocyte precursors leading to mature $\mathrm{T}$ and $\mathrm{B}$ cells leave the marrow as immature cells that immigrate into peripheral organs for further maturation (Heinzel et al. 2007). In the case of B cells, these are directly lymph nodes or the spleen (Moser et al. 2006). $T$ cell precursors first migrate into the thymus where they are screened for autoreactivity in a process of positive and negative selection before they enter the general circulation as mature naive T cells (Hogquist et al. 2005).

Newly produced $\mathrm{T}$ and $\mathrm{B}$ cells are functionally inactive. To become active, they need to physically interact with other cells, antigen presenting cells (APC) in the case of T cells or follicular dendritic cells (FDC) and $\mathrm{T}$ cells in the case of B cells. Such interactions require that the cells move effectively, since these interacting cells are initially spread over the entire body. Also the activation process itself requires active migration of T cells on the APC-surface and motility of the APC (Gunzer et al. 2000). If, e.g. the actin cytoskeleton of dendritic cells is inhibited, their function as APC is lost (Al-Alwan et al. 2001a, b).

As can be seen from these few examples, cell migration is a critical process for cellular immunity. The present review aims at giving a short overview of available technologies to investigate cell migration both in vitro and in vivo, as well as examples of biologically relevant information that can be drawn out of such experiments. Due to limitations 
in space, the text cannot give a comprehensive coverage of the whole field, as this is far too widespread. For more in-depth discussions of the subject, the reader should refer to several extensive reviews (Cahalan et al. 2002; Germain et al. 2006; Halin et al. 2005; Niesner et al. 2008). The present overview, instead, should spark the interest of the reader into this kind of research, which is both optically and scientifically fascinating.

\section{Analysis of cell migration in vitro}

There are a number of approaches to analyze cell migration in vitro. Cell isolation as high-cell purity is a critical step that is absolutely required when tracking individual cells directly, which will be the focus of this review.

Cell isolation is most conveniently done by immunmagnetic separation, which is both gentle to cells and rapid. Here, the cells of interest are labeled with a specific antibody (positive isolation) or all contaminating cells are labeled, leaving the cells of interest untouched (negative isolation) (Gunzer et al. 2001). The labeling antibodies are then attached to small paramagnetic particles and a strong magnet will retain the labeled cells that can then be separated from the unlabeled cells by simple pipetting or a column washing. A more advanced method is the use of an automated fluorescence activated cell sorter (FACS), which is able to pick individual cells from a constant flow at a very high rate based on their diffractive and fluorescent behavior. The method of cell tagging is similar to the immunmagnetic technique with the difference that the labeling antibodies are loaded with fluorescent dyes rather than magnetic particles. Since in the FACS cells are subjected to rapid fluidics, strong magnetic fields as well as to intense laser irradiation, the method is generally more stressful for cells. However, a FACS allows separation of cells based on more subtle parameters, such as intensity of staining, size or the combined appearance of more than one fluorescent marker. As a general rule, negative isolation techniques are superior to positive, as they leave the cells of interest untouched of potentially activating antibodies binding to the cell surface molecules (Gunzer et al. 2001). In many cases, the purity of cells that can be obtained with a good negative protocol is almost equivalent to positive approaches (Gunzer et al. 2001). However, positive approaches can be the only solution, if e.g., the cells of interest do express many common markers and only one identifying antigen or if cells are very rare.

When the cells of interest have been obtained with a reasonable purity, they can be subjected to at least two principally different assays to test their motility. The first type is a so-called end-point method. Here, cells are analyzed after they have migrated at defined conditions for a given amount of time. Depending on the method, often only a subfraction of cells is scored, e.g., the ones that have migrated the farthest. Cells that do not migrate or migrate too slowly are not counted although they clearly belong to the overall population. An example for such an end-point method of migration analysis is the Boyden chamber. Here, cells lie on a porous bottom and are allowed to migrate to a lower compartment along a gradient of a chemoattractant molecule. After completion of the assay, all cells in the lower compartment are counted (Boyden 1962).

A second approach is the use of direct observation of migrating cells by means of video-microscopy. This method allows the tracking of migrating cells thus providing information such as direction, velocity, pausing behavior, etc. (Germain et al. 2006; Reichardt et al. 2007). The direct observation also allows to investigate cell-cell interactions that is especially important when analyzing the function of immune cells (Gunzer 2007). For example, the duration of contacts between T cells and APC (Bousso and Robey 2003; Castellino et al. 2006; Gunzer et al. 2000, 2004; Mempel et al. 2004; Miller et al. 2004a; Shakhar et al. 2005), cytotoxic cells and their targets (Mempel et al. 2006; Stinchcombe et al. 2001) or B cells with antigen containing cells have been analyzed (Batista et al. 2001; Fleire et al. 2006).

An important consideration when analyzing cell migration in vitro is the choice of the right environment. In the body, cells migrate within 3D tissues most of the time, although some 2D environments such as the surface of blood vessels or, e.g., the alveoli of the lung are present (Behnsen et al. 2007). The major difference in these environments is that migration on 2D surfaces is dominated by adhesion-dependent events while migration in 3D, at least for leukocytes, is an adhesion-independent process of squeezing between matrix pores (Lammermann et al. 2008). A convenient way of providing a 3D environment for the analysis of cell migration in vitro is the use of hydrated gels of matrix proteins such as type I collagen or basement membrane (Matrigel ${ }^{\mathrm{TM}}$ ). These are easily generated and transparent and thus allow the use of high resolution microscopy for the imaging of cells (Huang et al. 2005; Reichardt et al. 2007). The use of fluorescent indicators of cell physiology, such as Calcium-sensitive dyes is also possible allowing the high-resolution imaging of cell signaling (Gunzer et al. 2000, 2004; Waibler et al. 2008).

\section{Analysis of cell migration in vivo}

Naturally, the physiologic conditions in true live tissues are far too complex to faithfully reconstruct them in any in vitro approach. Thus, the ultimate goal to understand cell migration in vivo is to actually investigate the process by 
direct observation in vivo. Intravital microscopy is by no means a new technology. In fact, the father of modern microscopes, the Dutch Antonie van Leeuwenhoek already at the end of the seventeenth century, investigated the blood flow in arteries and veins of animals as one of his first objects (Dobell 1922; van Leeuwenhoek 1688). Analysis of cells in the free-blood stream has been a stronghold in immunological research ever since leading to important concepts such as the multistep paradigm of leukocyte extravasation (Springer 1994), which even form the basis of modern anti-inflammatory therapy (Lutterotti and Martin 2008). Nevertheless, a real breakthrough in technology was achieved with the advent of modern laser scanning microscopy, especially of 2-photon microscopy (2PM) (Cahalan et al. 2002). Using high-intensity infrared laser-radiation, which can travel undiffractedly deeply into tissue, as a source for the excitation of fluorophores, this technique allows visualizing fluorescently labeled cells at high resolution, both in space and time. A very good review on the technical background of $2 \mathrm{PM}$ has been written by Cahalan et al. (2002).

2-Photon microscopy (2PM), as a technology for tissue analysis has been introduced by Denk et al. in 1990 (Denk et al. 1990) and initially was used mostly by neurobiologists (Denk et al. 1994). It was only by the beginning of 2000 that the use of 2PM for addressing immunological questions was proposed (Dustin et al. 2001). Shortly after this, the first papers investigating cell migration in explanted lymph nodes (Miller et al. 2002) or thymic stromal reaggregate cultures (Bousso et al. 2002) were published, followed by true intravital studies (Gunzer et al. 2004; Mempel et al. 2004). Meanwhile the number of reports using intravital 2PM for immunological questions has risen enormously, spanning from the cellular events of $\mathrm{T}$ cell activation (Miller et al. 2004a), formation and function of germinal centers (Allen et al. 2007b; Schwickert et al. 2007) or function of regulatory $\mathrm{T}$ cells (Tadokoro et al. 2006) to complex processes such as granuloma formation (Egen et al. 2008) and the delivery of antigens (Carrasco and Batista. 2007; Qi et al. 2006) or viruses to B cells (Junt et al. 2007a). Today, studies addressing dynamic features of immune cells, such as migration, phagocytosis or interaction with the environment can hardly be published in high-ranking journals without intravital imaging data.

Clearly, the in vivo approach bears the possibility to analyze cell migration in its most natural appearance. However, the drawback is the need for relatively complex and expensive equipment and the mastering of difficult animal experiments. In order to give the reader a feeling for the principal setup of intravital microscopy experiments with immune cells, we will describe the basic technical approach in the next section followed by examples about the type of information and biological insight that can be gained out of intravital experiments.

\section{Technical aspects of imaging}

Microscope

The choice for the microscopic equipment is highly dependent on the priorities of the individual researcher. Most major microscopy makers, meanwhile offer complete packages for intravital laser scanning microscopes including 2PM. In addition, there are independent companies that combine conventional microscopic hardware with selfconstructed parts, such as scanners or detection devices. Reviews of available technology can be found here (Germain et al. 2006; Niesner et al. 2008). When a new investment into a system is planned, it is highly advisable to intensively study all possible setups with own samples and own hands-on test runs. Suppliers usually have an own set of demo samples which will yield highly impressive images. However, those samples will not be able to tell whether the own preparations and the own questions have a good chance to be successfully addressed with the same system. In the following, we will give a brief overview of the experiences we have made over the past years. All modern intravital imaging setups rely on premium optical hardware, which is excellent from all suppliers we can oversee. Thus, the performance of the optical elements will most likely not differ extremely between the different systems. In our hands more dynamic, yet important features of a good system are:

(1) A large and easily adjustable sample area under the microscope lens (of an upright system, which is most often used for intravital microscopy) allowing the imaging, e.g., of lymph nodes (the sample area is relatively flat) or the brain (requiring much more space under the lens). This is especially important, if the new system is supposed to be part of a larger imaging core facility for general use.

(2) A stable focussing device allowing both rapid and highly reproducible Z-stacks over long periods of imaging. A motorized $X-Y$-scanning table is not mandatory but may allow the automated imaging of different sample areas such as for tile-scans of larger zones that do not fit into a single field of view.

(3) Excellent fluorescence detection systems with easily changeable filters. This can be either photomultipliers (PMT) or CCD cameras (Germain et al. 2006; Niesner et al. 2008). While the former have better signal to noise ratio and thus can get good images from deeper regions of a sample, the latter are typically much faster 
thus allowing real time imaging of really fast processes such as blood flow (Niesner et al. 2007) or nerve activity (Crepel et al. 2007). For PMT, the positioning within the light path is an important consideration. Ideally, the PMTs are positioned as closely behind the back aperture of the imaging lens as possible with the detected emission from the sample not being routed back over the scanning device (non-descaned-detection, NDD). However, modern detection systems also offer the possibility for total spectral analysis (after descanned detection, DD) of the incoming fluorescence light with the chance to freely adjust the detection range of any given PMT. This feature offers the possibility to better separate signals at the cost of lower detection efficiency.

(4) A stable and easily usable control software that gives not only rapid access to relatively simple imaging regimes but also allows for more complicated approaches with more ambitious imaging tasks. Similar to point (1) this is, especially important for systems running in general use core-facilities.

(5) Laser(s) with an as large as possible tuning range for 2PM. Modern single-box Titanium-Sapphire lasers offer a tuning range from 690 up to $1,080 \mathrm{~nm}$. Recently, the use of so-called optical parametric oscillators (OPO), which offer tuning ranges above $1,100 \mathrm{~nm}$ has been described to offer advantages in terms of imaging depths and low phototoxicity, but this possibility is currently offered by only one commercial supplier (Büttner et al. 2007). If funds are sufficient, it makes sense to equip the system with a second, independent 2P-laser allowing for the simultaneous use of two independent excitation wavelengths which would allow a better separation of red and green fluorescence proteins (Kawano et al. 2008).

Depending on the dyes used for labeling of the cells and the type of tissue imaged the wavelength for 2PM excitation is chosen. There is no general law as to which wavelength is optimal for a given sample. Finding the right value is always a matter of experimentation. Since longer (=red shifted) wavelengths are less phototoxic (Konig 2000), a rule of thumb is that the longest wavelength should be chosen that still allows clear detection and separation of all necessary signals. Imaging can then be performed in a number of different ways using single or multiple focal planes, time points and detected emission wavelengths from the sample. If a sample is imaged for the first time it does make sense to also detect all emitted fluorescence light at once, to see whether an autofluorescent signal generated from the sample (e.g. of aromatic biomolecules in cells) can yield useful information (Konig 2000; Niesner et al. 2007, 2008).

\section{Storage and analysis}

Despite the recording of optically perfect images and image sequences, it is important to consider the storage and the proper analysis of the data. Storage solutions should provide space in the multi terabyte range. Ideally, systems can be set up where a central storage server is accessible from the microscopy control computer as well as by one or multiple analysis systems via fast networking, e.g., a gigabit-backbone Ethernet. This allows using the microscope computer only for data generation thereby maximizing the duty time of its expensive imaging hardware. The data analysis can be done off-line on separate work stations, which can be optimized to run the complex and resource-hungry analysis tools. In addition, a central server that is mirrored and regularly backed up by a professional computing center offers a much higher data safety standard than solutions where data storage and backup is in the hands of individual users.

Analysis of the data is a very complex issue, which can not be covered here in its entirety. In fact, with more and more complex multi-dimensional data sets being generated, the area of data analysis alone is a field of active research (Nath et al. 2006; Sacan et al. 2008). It is very much dependent on the type of question being asked, what type of analysis is required and to what degree it can be automated. While calcium waves in neuronal networks or optical colocalizations in fixed or non-moving tissues can be readily analyzed with existing software tools (Crepel et al. 2007; Gobel et al. 2007), the analysis of cell migration or cellcell contact formation is still not done properly by existing software and, in fact, is done manually or at least with heavy manual verification till today (Hauser et al. 2007).

\section{Anesthesia of experimental animals}

There are two frequently used ways of anesthesia for in vivo imaging of mice. The first way is the injection of anesthetic drugs like ketamine/rompun intraperitoneally (Hauser et al. 2007; Mempel et al. 2004). The advantage of this strategy is the simple application, but the disadvantage is the necessity for repeated applications of anesthetic to maintain a deep level of anesthesia during preparation and imaging. Furthermore it was described that the application of anesthetic agents like ketalar induces the release of multiple proinflammatory cytokines in human leukocytes in vitro (Rossano et al. 1992). The release of such cytokines is likely to affect the immune responses that are being analyzed. The second way of narcosis is inhalation-anesthesia using volatile anesthetics. Today, the main anesthetic used for inhalation-anesthesia is isoflurane (IF). The method of supply can vary. Experimental animals are either supplied with a $1-2 \%$ concentration of IF in $\mathrm{O}_{2} /$ air by an inhalation 
mask (Qi et al. 2006) or the animals are intubated and get a similar mixture of the anesthetic by mechanical ventilation (Gunzer et al. 2004; Niesner et al. 2007). In our hands, the latter approach is the most suitable method for long-term imaging experiments, since it allows a very precise and tunable application of narcosis. Although IF is probably less inflammatory than injection narcosis, it also leads to mild increases of cytokine production in human patients (Brand et al. 1998) and thus will also impact on the cellular mechanisms under investigation.

For both the strategies, it is essential to check the level of narcosis, e.g., by pinching the tail and by checking body and whisker movements or by monitoring blood flow and pressure before starting the preparation of lymphoid tissues and permanently during the imaging procedure.

\section{Visualization of leukocytes and organ structure}

In most in vivo imaging experiments, fluorescent isolated cells are adoptively transferred into recipient animals. To allow the visualization of lymphocytes in experimental animals, it is necessary to have the right fluorescent probe. These probes have to fulfil requirements like low leakage from stained cells, no alteration of the phenotype or function of the cells and high photostability. Ideally, dyes also exhibit a narrow range of emission that allows easy separation from other color channels. CellTracker ${ }^{\mathrm{TM}}$ dyes fulfil the above mentioned requirements to a high degree. Thus, they are routinely used for labeling of whole cells for long-term imaging in vivo and in vitro. The advantage of this method is a relatively simple and cost-effective means to distinguish different cell types after adoptive transfer in vivo (Fig. 1f). However, chemical labeling, although simple and bright, is not suitable for long-term imaging of dividing cells, such as $\mathrm{T}$ cells or B cells in ongoing immune reactions. This is due to the fact that a limited amount of colored molecules gets equally distributed between daughter cells at each proliferation cycle, rapidly leading to unstained cells after a few rounds of division (Miller et al. 2002).

To overcome this limitation, people have developed a large number of transgenic animals expressing genetically encoded fluorescent markers like GFP or its variants (Chalfie et al. 1994; Shaner et al. 2005) (XFP). Apart from being stable over an indefinite number of cell divisions, this approach also offers several other advantages: (1) combinatorial expression of mixtures of different XFP allows the staining of individual cells in all colors of the visible spectrum within the same animal (Livet et al. 2007), (2) expression driven by defined promoters enables cell type-specific labeling, such as the network of dendritic cells in peripheral lymphatic tissues (Lindquist et al. 2004) or microglia in the brain (Jung et al. 2000), (3) the same approach can also lead to development-specific expression of XFP, such as in BLIMP1-GFP mice, that harbor green plasma cells of the B lineage (Kallies et al. 2004) and finally (4) the fusion of XFP with organelle-specific proteins or localization signals can lead to stable fluorescent staining of the target structures, such as mitochondria (Misgeld et al. 2007) or the DNA in the nucleus (Hadjantonakis and Papaioannou 2004). (5) Another useful approach, based on XFP is the generation of genetically encoded sensors that, e.g., allow cell-type-specific calcium imaging in vivo without the need of dye application (Wallace et al. 2008).

XFP transgenic cells can principally be studied without the need for adoptive transfer. For example, Lindquist et al. (2004) have shown that, using transgenic mice with dendritic cell (DC)-specific expression of enhanced YFP, DCs are enmeshed in an extensive network and remain in place within peripheral lymph nodes in vivo. Kallies et al. (2004) used transgenic mice, where GFP was targeted to the Blimpl locus, to analyze the kinetics and cellular subtypes of plasma cell differentiation (Kallies et al. 2004). However, it is not always advisable to use XFP-transgenic mice directly or choose a model where all cells of a given lineage express the XFP-protein for imaging. For example, the germinal center (GC) reaction that is responsible for the development of affinity-matured antibodies (Allen et al. 2007a) relies on multiple rounds of $\mathrm{B}$ cell divisions. Transferring a population of naive antigen-specific $B$ cells that all express GFP into a host leads to completely green GC several days after the injection of the B cell-specific antigen which does not allow distinguishing individual migrating cells within the GC. In this case, it is necessary to "dilute" the GFPtransgenic cells up to $90 \%$ with GFP-non-transgenic counterparts (Hauser et al. 2007).

While XFP-based approaches are very versatile, there may apply limitations to label particular cell types. A good example for this problem is follicular dendritic cells (FDC) that form the antigenic repository in GC (Kosco-Vilbois 2003). Up to now, there is no highly-specific FDC promoter known. Thus, XFP-based approaches to label the FDC network rely on complicated strategies of radiation chimaeras exploiting the ability of FDC to resist radiation-mediated ablation (Bajenoff et al. 2006; Victoratos et al. 2006). In contrast, a very simple, yet functional approach to stain FDC is the injection of FDC-specific fluorescent antibodies subcutaneously (Schwickert et al. 2007) (Fig. 1e).

Imaging fluorescent cells within tissues also requires knowledge of the surrounding organ structure. Two approaches are particularly useful to obtain this task. (1) By injection of fluorescently labeled high-molecular weight dextran into the blood stream, blood flow can be very nicely visualized (Junt et al. 2007b). If a small organic dye such as Rhodamine 6G is used directly, it is possible to dye-label all cellular components in the blood stream as 
Fig. 1 2-Photon view into the B cell zone of an inguinal lymph node. B cells were isolated from the spleen of donor mice, stained with cell tracker orange (red) and transferred i.v. into recipients. Twenty-four hours before imaging, recipients were injected s.c. in the flank with the antibody FDC-M1 that was conjugated to AlexaFluor-488 (green). The cortex of the inguinal lymph node was visualized by measuring SHG (gray). a-d Represent $X-Z$ views of the same region that is depicted as $X-Y$ view in $\mathbf{e}-\mathbf{h}$. $\mathbf{a}, \mathbf{b}$ and $\mathbf{e}-\mathbf{g}$ represent singlechannel views of the individually detected colors/ structures. $\mathbf{c}$ is a combination of the FDC/B cell channel and $\mathbf{d}$ and $\mathbf{h}$ are merged images of all detected colors showing the complexity of the lymph node architecture
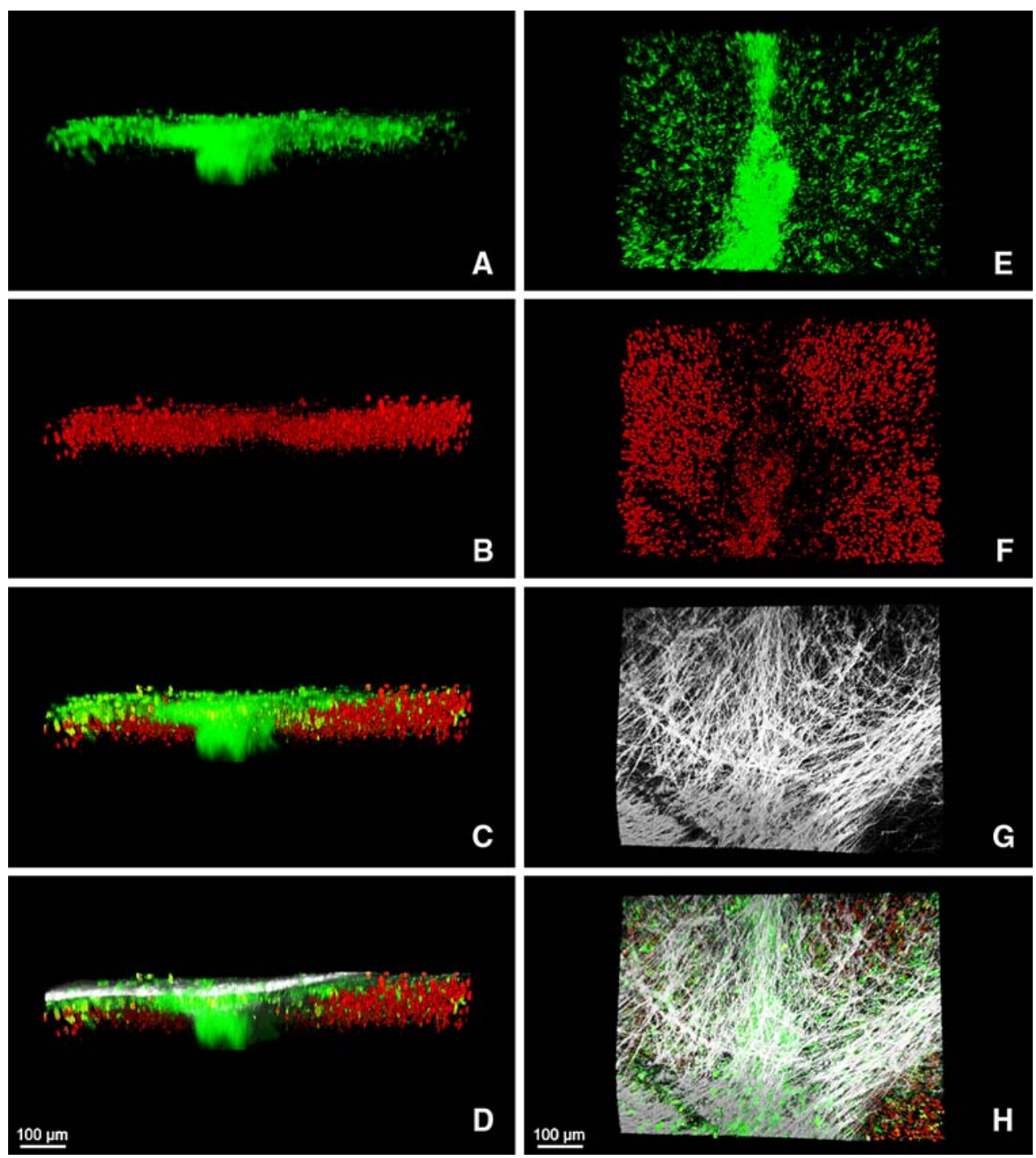

well as the peripheral cells surrounding the blood vessels, due to leakage of the dye into the embedding tissues (Niesner et al. 2007). (2) 2-Photon microscopy can exploit a behavior of matrix fibers, especially those made of type 1 collagen, to react to the laser excitation in a process called non-linear interaction, leading to frequency doubling and, consequently, wavelength halving of the reflected incoming radiation. This process is called second harmonic generation (SHG) and gives excellent contrast of fibrous extracellular matrix in solid organs without the need for specific additional staining (Zoumi et al. 2002). SHG can be used to visualize the cortex and deeper regions of the lymphatic tissue of lymph nodes (Fig. 1g).

\section{Imaging of lymphoid tissues}

The inguinal lymph node has a large size and is easy to prepare. Therefore, many imaging studies were done in this lymph node (Lindquist et al. 2004; Miller et al. 2003; Okada et al. 2005). For its preparation, the experimental animal is transferred to a heated platform or water bath. After removal of the abdominal hair, the skin is incised from the edge of the rib cage through the midline to the thigh. A skin flap is separated from the peritoneal skin and fixed by needles exposing the lymph node, thereby taking care not to suppress the blood flow. To fully expose the lymph node, the covering skin fat needs to be carefully removed with fine forceps. Then, the lymph node is immersed in $37^{\circ} \mathrm{C}$ prewarmed physiological $\mathrm{NaCl}$-solution or PBS and the imaging is started. The greatest problem of imaging inguinal lymph nodes is the respiration-induced tissue movement that must be mechanically constrained. Secondly, the inguinal lymph node is very large, which makes the preparation relatively easy but leads to limited penetration of the exciting laser-light as well as the fluorescence coming out of the sample. Another problem is the routing of biological material (cells or antigen), specific to 
this lymph node. After application of antigen into the flank skin of the experimental animal, the amount that reaches the inguinal lymph node is difficult to control since the lymphatic vessels draining the area of injection not only supply the inguinal lymph node but also several more distal nodes (Palframan et al. 2001) (Abraham et al. 1999).

Less invasive is the preparation of the popliteal lymph node, which has been pioneered by Mempel et al. (2004). Here, skeletal pivots are fixation points for near-perfect immobilization. Furthermore, the popliteal lymph node is more accessible for deep imaging. Because of the small size, it is possible to see the cortex as well as the medullary region. In addition, application of antigens or cells into a footpad leads to a highly specific transport of the material to the popliteal lymph node draining this leg (Mempel et al. 2004).

Both lymph node preparations have yielded similar values for the migratory activity of DC and T cells (Lindquist et al. 2004; Mempel et al. 2004; Miller et al. 2004b). The in vivo measurements of cell migration and communication are also in good agreement with microscopy studies performed in situ in excised, intact murine LNs (Bousso and Robey 2003). However, such in situ imaging studies require careful control of the environment for temperature and supply with gases (Huang et al. 2007). Furthermore, it is not clear whether the absence of innervation, lymph-, and blood-flow affects cellular functions at a more subtle level. For example, the number of circulating hematopoietic stem cells has been found to depend on circadian rhythms of the sympathetic nervous system controlling the bone marrow (Mendez-Ferrer et al. 2008) and the function of lymph node $\mathrm{T}$ cells in hapten hypersensitivity reactions is controlled by neuropeptides produced by lymph-node infiltrating nerve endings (Shepherd et al. 2005). On the other hand, intravital microscopy, while being the best method for understanding biological processes in an in vivo situation, requires sophisticated instrumentation and knowhow for preparation or anesthesia of experimental animals and all the treatments necessary to obtain good images in live animals will also influence the biology of the processes under investigation.

\section{Impact of imaging studies on cell migration for understanding the biology of immune responses}

Compared to conventional confocal approaches, 2PM provides an enhanced imaging depth and allows $4 \mathrm{D}(X, Y, Z, t)$ imaging for observing dynamic processes deep in native tissues in vivo (Niesner et al. 2007, 2008). There are now many groups using 2PM for dynamic imaging of immune cell motility, interactions and clustering in vivo (Cahalan and Gutman 2006). Since its start in 2002 (Bousso et al.
2002; Miller et al. 2002), 2PM of lymphatic tissue has become very popular among immunologists. The number of reports meanwhile counts in the hundreds. Thus, it is no longer possible to give a comprehensive overview. Instead, we chose to mention our selection of highlights, thereby focusing on studies done in lymph nodes.

The germinal center (GC) reaction is a prototypical example where direct imaging was able to tackle a longstanding problem. The GC is a structure in lymph nodes forming during antigen-specific B cell responses. It is composed of a so-called light zone and a dark zone based on its appearance in histological sections (Allen et al. 2007a). In the dark zone, a maturation state of antigen-specific B cells called centroblasts proliferates and hypermutates the antibody genes to generate antibody diversity. A successfully generated new antibody molecule is then presented on the cell surface as a transmembrane protein, the $\mathrm{B}$ cell receptor (BCR). The quality of a chance-derived new antibody specificity is then "tested" by each centroblast, by migration into the light zone where many FDCs are positioned to present cognate antigen in the form of immune complexes (Meyer-Hermann and Maini 2005). B cells in the light zone are called centrocytes. When its newly generated BCR is unable to bind the cognate antigen on the FDC surface, the centrocyte is prone to die by apoptosis. Otherwise, it gets a survival signal and can ultimately develop in an antibodyproducing plasma cell or a memory B cell. For a long time, it was a matter of debate whether there was the possibility for centrocytes to become centroblasts again and go back from the light- to the dark zone in a process called recirculation or recycling (Meyer-Hermann and Maini 2005). It was only possible to address by direct imaging of the GC reaction, what is actually happening and, consequently, one of the prime targets of the first set of three imaging studies on the germinal center response was the analysis of just this parameter (Allen et al. 2007b; Hauser et al. 2007; Schwickert et al. 2007). However, this example also demonstrates the difficulties in coming to generally accepted conclusions. Although, all three studies detected frequent crossing of the interzone boundary in the same frequency range, they interpreted their results very differently, basically coming to opposite conclusions about their meaning. Thus, in cases like these, imaging alone will not consistently solve scientific questions. This is why mathematical modeling of the obtained imaging data can help to come to new predictions about different models which can then be tested by new imaging studies (Meyer-Hermann et al. 2006).

Another field of intense research, probably with fewer disputes over the results, is $\mathrm{T}$ cell activation by antigen presenting cells (APC). It was essentially this topic which was addressed first by immunologists using $2 \mathrm{PM}$ in lymphatic tissues (Miller et al. 2002). The basic question was coming out of in vitro studies showing for the first time 
the interactions of T cells with APC. While it was known that $\mathrm{T}$ cells require approximately $20 \mathrm{~h}$ of stimulation by APC before they are fully committed to proliferation (Iezzi et al. 1998), it was not clear how the $T$ cells behave during this activation. However, it was generally believed that $\mathrm{T}$ cells would permanently bind to a single APC throughout this time. Thus, it came as a great surprise when it was shown that $\mathrm{T}$ cell that contact dendritic cells, although very efficient for $\mathrm{T}$ cell activation, were highly dynamic and short-lived in artificial 3D matrix based environments (Gunzer et al. 2000). Thus, imaging in explanted lymhnodes (Miller et al. 2002) and later in vivo, (Mempel et al. 2004) primarily addressed the question, whether stimulating T-APC contacts are dynamic or stable and led to the discovery that the real $\mathrm{T}$ cell activation process is a mixture of more dynamic and more static interaction phases (Mempel et al. 2004; Miller et al. 2004a, b). Multiple papers have meanwhile confirmed these initial findings and the "phase model" of $\mathrm{T}$ cell activation is currently widely accepted, although, under given circumstances the duration and physiology of such phases might drastically change (Celli et al. 2007; Henrickson et al. 2008).

Finally, a very interesting and fruitful field for intravital research is the function of innate immune cells during infection defence. Using intravital microscopy, the lab of Ron Germain has demonstrated the dynamics of granuloma formation (Egen et al. 2008) and the fantastic dynamic action of endogenous neutrophils towards an infection with Leishmania major (Peters et al. 2008). Here, the intravital imaging was able to directly prove parts of a previous hypothesis on a "trojan horse" mechanism (van Zandbergen et al. 2007) by which L. major might overcome the innate host defence for establishment of a successful infection.

\section{Outlook}

Intravital imaging has become a stronghold in immunologic research. Roughly 6 years after the first publications, the field is in its first period of prosperity delivering new fascinating insights into the dynamic actions of working immune cells almost on a daily basis. The future directions should now push the limits of the technology to better penetration, longer imaging periods or repeated imaging of the same structure, if its development is in the range of days or weeks such as with GCs. It will also be important to include the analysis of physiologic signaling by means of specifically designed biosensors (Jose et al. 2007; Nair et al. 2006). This will ultimately lead to a much more realistic picture of cellular immune responses. Clearly, "dynamic content" will accompany papers, text books and public talks from the field of immunology for many years to come.
Acknowledgments This study was supported by the Deutsche Forschungsgemeinschaft (SPP 1160 (GU 769/1-2 and GU 769/1-3) to M.G.), by the German Ministry for Education and Research (BMBF, Bioprofile) to M.G. and by the European Union (Grant 043243, MAMOCELL) to M.G. and M.K-V. We thank Mike Hasenberg for help with the generation of images.

\section{References}

Abraham C, Griffith J, Miller J (1999) The dependence for leukocyte function-associated antigen-1/ICAM-1 interactions in T cell activation cannot be overcome by expression of high density TCR ligand. J Immunol 162:4399-4405

Al-Alwan MM, Rowden G, Lee TD, West KA (2001a) Cutting edge: the dendritic cell cytoskeleton is critical for the formation of the immunological synapse. J Immunol 166:1452-1456

Al-Alwan MM, Rowden G, Lee TD, West KA (2001b) Fascin is involved in the antigen presentation activity of mature dendritic cells. J Immunol 166:338-345

Allen CD, Okada CY, Cyster JG (2007a) Germinal-center organization and cellular dynamics. Immunity 27:190-202

Allen CD, Okada T, Tang HL, Cyster JG (2007b) Imaging of germinal center selection events during affinity maturation. Science 315:528-531

Bajenoff M, Egen JG, Koo LY, Laugier JP, Brau F, Glaichenhaus N, Germain RN (2006) Stromal cell networks regulate lymphocyte entry, migration, and territoriality in lymph nodes. Immunity 25:989-1001

Batista FD, Iber D, Neuberger MS (2001) B cells acquire antigen from target cells after synapse formation. Nature 411:489-494

Behnsen J, Narang P, Hasenberg M, Gunzer F, Bilitewski U, Klippel N, Rohde M, Brock M, Brakhage AA, Gunzer M (2007) Environmental dimensionality controls the interaction of phagocytes with the pathogenic fungi Aspergillus fumigatus and Candida albicans. PLoS Pathog 3:e13

Bousso P, Robey E (2003) Dynamics of CD8(+) T cell priming by dendritic cells in intact lymph nodes. Nat Immunol 4:579-585

Bousso P, Bhakta NR, Lewis RS, Robey E (2002) Dynamics of thymocyte-stromal cell interactions visualized by two-photon microscopy. Science $296: 1876-1880$

Boyden S (1962) The chemotactic effect of mixtures of antibody and antigen on polymorphonuclear leucocytes. J Exp Med 115:453-466

Brand JM, Kirchner H, Poppe C, Schmucker P (1998) Cytokine release and changes in mononuclear cells in peripheral blood under the influence of general anesthesia. Anaesthesist 47:379-386

Büttner E, Andresen V, Rimke I, Friedl P (2007) Infrared multiphoton microscopy beyond 1 micron: system design and biomedical applications. Progress in biomedical optics and imaging. In: Proceedings of SPIE 8:663000H

Cahalan MD, Gutman GA (2006) The sense of place in the immune system. Nat Immunol 7:329-332

Cahalan MD, Parker I, Wei SH, Miller MJ (2002) Two-photon tissue imaging: seeing the immune system in a fresh light. Nat Rev Immunol 2:872-880

Carrasco YR, Batista FD (2007) B cells acquire particulate antigen in a macrophage-rich area at the boundary between the follicle and the subcapsular sinus of the lymph node. Immunity 27:160-171

Castellino F, Huang AY, tan-Bonnet G, Stoll S, Scheinecker C, Germain RN (2006) Chemokines enhance immunity by guiding naive $\mathrm{CD} 8+\mathrm{T}$ cells to sites of CD4+ T cell-dendritic cell interaction. Nature 440:890-895

Celli S, Lemaitre F, Bousso P (2007) Real-time manipulation of T celldendritic cell interactions in vivo reveals the importance of 
prolonged contacts for $\mathrm{CD} 4(+) \mathrm{T}$ cell activation. Immunity 27:625-634

Chalfie M, Tu Y, Euskirchen G, Ward WW, Prasher DC (1994) Green fluorescent protein as a marker for gene expression. Science 263:802-805

Crepel V, Aronov D, Jorquera I, Represa A, Ben-Ari Y, Cossart R (2007) A parturition-associated nonsynaptic coherent activity pattern in the developing hippocampus. Neuron 54:105-120

De FK, Henderson RB, Laschinger M, Hogg N (2008) Neutrophil chemokines $\mathrm{KC}$ and macrophage-inflammatory protein-2 are newly synthesized by tissue macrophages using distinct TLR signaling pathways. J Immunol 180:4308-4315

Denk W, Strickler JH, Webb WW (1990) Two-photon laser scanning fluorescence microscopy. Science 248:73-76

Denk W, Delaney KR, Gelperin A, Kleinfeld D, Strowbridge BW, Tank DW, Yuste R (1994) Anatomical and functional imaging of neurons using 2-photon laser scanning microscopy. J Neurosci Methods 54:151-162

Dobell C (1922) Antony van Leeuwenhoek and his "Little Animals": Being some account of the father of protozoology and bacteriology and his multifarious discoveries in these disciplines. Harcourt, Brace and Company, New York

Dustin ML, Allen PM, Shaw AS (2001) Environmental control of immunological synapse formation and duration. Trends Immunol 22:192-194

Egen JG, Rothfuchs AG, Feng CG, Winter N, Sher A, Germain RN (2008) Macrophage and T cell dynamics during the development and disintegration of mycobacterial granulomas. Immunity 28:271-284

Fleire SJ, Goldman JP, Carrasco YR, Weber M, Bray D, Batista FD (2006) B cell ligand discrimination through a spreading and contraction response. Science 312:738-741

Geiger H, Koehler A, Gunzer M (2007) Stem cells, aging, niche, adhesion and CDC42: a model for changes in cell-cell interactions and hematopoietic stem cell aging. Cell Cycle 6:884-887

Germain RN, Miller MJ, Dustin ML, Nussenzweig MC (2006) Dynamic imaging of the immune system: progress, pitfalls and promise. Nat Rev Immunol 6:497-507

Gobel W, Kampa BM, Helmchen F (2007) Imaging cellular network dynamics in three dimensions using fast 3D laser scanning. Nat Methods 4:73-79

Gunzer M (2007) Migration, cell-cell interaction and adhesion in the immune system. Ernst Schering Found Symp Proc 3:97-137

Gunzer M, Schäfer A, Borgmann S, Grabbe S, Zänker KS, Bröcker EB, Kämpgen E, Friedl P (2000) Antigen presentation in extracellular matrix: interactions of T cells with dendritic cells are dynamic, short lived, and sequential. Immunity 13:323-332

Gunzer M, Weishaupt C, Planelles L, Grabbe S (2001) 2-Step negative enrichment of $\mathrm{CD}^{+}$and $\mathrm{CD} 8^{+} \mathrm{T}$ cells from murine spleen via nylon wool adherence and an optimized antibody cocktail. J Immunol Methods 258:55-63

Gunzer M, Weishaupt C, Hillmer A, Basoglu Y, Friedl P, Dittmar KE, Kolanus W, Varga G, Grabbe S (2004) A spectrum of biophysical interaction modes between $\mathrm{T}$ cells and different antigen presenting cells during priming in 3 -D collagen and in vivo. Blood 104:2801-2809

Hadjantonakis AK, Papaioannou VE (2004) Dynamic in vivo imaging and cell tracking using a histone fluorescent protein fusion in mice. BMC Biotechnol 4:33

Halin C, Rodrigo MJ, Sumen C, von Andrian UH (2005) In vivo imaging of lymphocyte trafficking. Annu Rev Cell Dev Biol 21:581-603

Hauser AE, Junt T, Mempel TR, Sneddon MW, Kleinstein SH, Henrickson SE, von Andrian UH, Shlomchik MJ, Haberman AM (2007) Definition of germinal-center B cell migration in vivo reveals predominant intrazonal circulation patterns. Immunity 26:1-13
Heinzel K, Benz C, Martins VC, Haidl ID, Bleul CC (2007) Bone marrow-derived hemopoietic precursors commit to the $\mathrm{T}$ cell lineage only after arrival in the thymic microenvironment. J Immunol 178:858-868

Henrickson SE, Mempel TR, Mazo IB, Liu B, Artyomov MN, Zheng H, Peixoto A, Flynn MP, Senman B, Junt T, Wong HC, Chakraborty AK, von Andrian UH (2008) T cell sensing of antigen dose governs interactive behavior with dendritic cells and sets a threshold for T cell activation. Nat Immunol 9:282-291

Hogquist KA, Baldwin TA, Jameson SC (2005) Central tolerance: learning self-control in the thymus. Nat Rev Immunol 5:772-782

Huang NN, Han SB, Hwang IY, Kehrl JH (2005) B cells productively engage soluble antigen-pulsed dendritic cells: visualization of live-cell dynamics of B cell-dendritic cell interactions. J Immunol 175:7125-7134

Huang JH, Cardenas-Navia LI, Caldwell CC, Plumb TJ, Radu CG, Rocha PN, Wilder T, Bromberg JS, Cronstein BN, Sitkovsky M, Dewhirst MW, Dustin ML (2007) Requirements for T lymphocyte migration in explanted lymph nodes. J Immunol 178:77477755

Iezzi G, Karjalainen K, Lanzavecchia A (1998) The duration of antigenic stimulation determines the fate of naive and effector T cells. Immunity 8:89-95

Jose M, Nair DK, Reissner C, Hartig R, Zuschratter W (2007) Photophysics of Clomeleon by FLIM: discriminating excited state reactions along neuronal development. Biophys J 92:2237-2254

Jung S, Aliberti J, Graemmel P, Sunshine MJ, Kreutzberg GW, Sher A, Littman DR (2000) Analysis of fractalkine receptor CX(3)CR1 function by targeted deletion and green fluorescent protein reporter gene insertion. Mol Cell Biol 20:4106-4114

Junt T, Moseman EA, Iannacone M, Massberg S, Lang PA, Boes M, Fink K, Henrickson SE, Shayakhmetov DM, Di Paolo NC, Van RN, Mempel TR, Whelan SP, von Andrian UH (2007a) Subcapsular sinus macrophages in lymph nodes clear lymph-borne viruses and present them to antiviral B cells. Nature 450:110-114

Junt T, Schulze H, Chen Z, Massberg S, Goerge T, Krueger A, Wagner DD, Graf T, Italiano JE Jr, Shivdasani RA, von Andrian UH (2007b) Dynamic visualization of thrombopoiesis within bone marrow. Science 317:1767-1770

Kallies A, Hasbold J, Tarlinton DM, Dietrich W, Corcoran LM, Hodgkin PD, Nutt SL (2004) Plasma cell ontogeny defined by quantitative changes in blimp-1 expression. J Exp Med 200:967-977

Kawano H, Kogure T, Abe Y, Mizuno H, Miyawaki A (2008) Twophoton dual-color imaging using fluorescent proteins. Nat Methods 5:373-374

Konig K (2000) Multiphoton microscopy in life sciences. J Microsc 200(Pt 2):83-104

Kosco-Vilbois MH (2003) Opinion: Are follicular dendritic cells really good for nothing? Nat Rev Immunol 3:764-769

Lammermann T, Bader BL, Monkley SJ, Worbs T, Wedlich-Soldner R, Hirsch K, Keller M, Forster R, Critchley DR, Fassler R, Sixt M (2008) Rapid leukocyte migration by integrin-independent flowing and squeezing. Nature 453:51-55

van Leeuwenhoek A (1688) Den waaragtigen omloop des bloeds, als mede dat de arterien en venae gecontinueerde bloed-vaten zijn, klaar voor de oogen gestelt. Verhandelt in een Brief, geschreven aam de Koninglyke Societeit tot Londen, pp 1-30

Lindquist RL, Shakhar G, Dudziak D, Wardemann H, Eisenreich T, Dustin ML, Nussenzweig MC (2004) Visualizing dendritic cell networks in vivo. Nat Immunol 5:1243-1250

Livet J, Weissman TA, Kang H, Draft RW, Lu J, Bennis RA, Sanes JR, Lichtman JW (2007) Transgenic strategies for combinatorial expression of fluorescent proteins in the nervous system. Nature 450:56-62

Lutterotti A, Martin R (2008) Getting specific: monoclonal antibodies in multiple sclerosis. Lancet Neurol 7:538-547 
Mempel TR, Henrickson SE, von Andrian UH (2004) T-cell priming by dendritic cells in lymph nodes occurs in three distinct phases. Nature 427:154-159

Mempel TR, Pittet MJ, Khazaie K, Weninger W, Weissleder R, von Boehmer H, von Andrian UH (2006) Regulatory T cells reversibly suppress cytotoxic $\mathrm{T}$ cell function independent of effector differentiation. Immunity 25:129-141

Mendez-Ferrer S, Lucas D, Battista M, Frenette PS (2008) Haematopoietic stem cell release is regulated by circadian oscillations. Nature 452:442-447

Meyer-Hermann ME, Maini PK (2005) Cutting edge: back to "one-way" germinal centers. J Immunol 174:2489-2493

Meyer-Hermann ME, Maini PK, Iber D (2006) An analysis of B cell selection mechanisms in germinal centers. Math Med Biol 23:255-277

Miller MJ, Wei SH, Parker I, Cahalan MD (2002) Two-photon imaging of lymphocyte motility and antigen response in intact lymph node. Science 296:1869-1873

Miller MJ, Wei SH, Cahalan MD, Parker I (2003) Autonomous T cell trafficking examined in vivo with intravital two-photon microscopy. Proc Natl Acad Sci USA 100:2604-2609

Miller MJ, Hejazi AS, Wei SH, Cahalan MD, Parker I (2004a) T cell repertoire scanning is promoted by dynamic dendritic cell behavior and random $\mathrm{T}$ cell motility in the lymph node. Proc Natl Acad Sci USA 101:998-1003

Miller MJ, Safrina O, Parker I, Cahalan MD (2004b) Imaging the single cell dynamics of CD4+ T cell activation by dendritic cells in lymph nodes. J Exp Med 200:847-856

Misgeld T, Kerschensteiner M, Bareyre FM, Burgess RW, Lichtman JW (2007) Imaging axonal transport of mitochondria in vivo. Nat Methods 4:559-561

Moser K, Tokoyoda K, Radbruch A, MacLennan I, Manz RA (2006) Stromal niches, plasma cell differentiation and survival. Curr Opin Immunol 18:265-270

Nair DK, Jose M, Kuner T, Zuschratter W, Hartig R (2006) FRETFLIM at nanometer spectral resolution from living cells. Opt Express 14:12217-12229

Nath SK, Bunyak F, Palaniappan K (2006) Robust tracking of migrating cells using four-color level set segmentation. Lect Notes Comput Sci 4179:920-932

Niesner RA, Andresen V, Neumann J, Spiecker H, Gunzer M (2007) The power of single- and multibeam 2-photon microscopy for high-resolution and high-speed deep tissue and intravital imaging. Biophys J 93:2519-2529

Niesner RA, Andresen V, Gunzer M (2008) Intravital 2-photon microscopy - focus on speed and time resolved imaging modalities. Immunol Rev 221:7-25

Okada T, Miller MJ, Parker I, Krummel MF, Neighbors M, Hartley SB, O'Garra A, Cahalan MD, Cyster JG (2005) Antigen-engaged $\mathrm{B}$ cells undergo chemotaxis toward the $\mathrm{T}$ zone and form motile conjugates with helper t cells. PLoS Biol 3:e150

Palframan RT, Jung S, Cheng G, Weninger W, Luo Y, Dorf M, Littman DR, Rollins BJ, Zweerink H, Rot A, von Andrian UH (2001) Inflammatory chemokine transport and presentation in HEV: a remote control mechanism for monocyte recruitment to lymph nodes in inflamed tissues. J Exp Med 194:1361-1373

Peters NC, Egen JG, Secundino N, Debrabant A, Kimblin N, Kamhawi S, Lawyer P, Fay MP, Germain RN, Sacks D (2008) In vivo imaging reveals an essential role for neutrophils in leishmaniasis transmitted by sand flies. Science 321:970-974

Qi H, Egen JG, Huang AY, Germain RN (2006) Extrafollicular activation of lymph node B cells by antigen-bearing dendritic cells. Science 312:1672-1676

Reichardt P, Gunzer F, Gunzer M (2007) Analyzing the physicodynamics of immune cells in a 3-D collagen matrix. Methods Mol Biol 380:253-269

Rossano F, Tufano R, Cipollaro de L'Ero G, Servillo G, Baroni A, Tufano MA (1992) Anesthetic agents induce human mononuclear leucocytes to release cytokines. Immunopharmacol Immunotoxicol 14:439-450

Sacan A, Ferhatosmanoglu H, Coskun H (2008) Cell track: an opensource software for cell tracking and motility analysis. Bioinformatics 24:1647-1649

Schwickert TA, Lindquist RL, Shakhar G, Livshits G, Skokos D, Kosco-Vilbois MH, Dustin ML, Nussenzweig MC (2007) In vivo imaging of germinal centres reveals a dynamic open structure. Nature 446:83-87

Shakhar G, Lindquist RL, Skokos D, Dudziak D, Huang JH, Nussenzweig MC, Dustin ML (2005) Stable T cell-dendritic cell interactions precede the development of both tolerance and immunity in vivo. Nat Immunol 6:707-714

Shaner NC, Steinbach PA, Tsien RY (2005) A guide to choosing fluorescent proteins. Nat Methods 2:905-909

Shepherd AJ, Beresford LJ, Bell EB, Miyan JA (2005) Mobilisation of specific $\mathrm{T}$ cells from lymph nodes in contact sensitivity requires substance P. J Neuroimmunol 164:115-123

Springer TA (1994) Traffic signals for lymphocyte recirculation and leukocyte emigration: the multistep paradigm. Cell 76:301-314

Stinchcombe JC, Bossi G, Booth S, Griffiths GM (2001) The immunological synapse of CTL contains a secretory domain and membrane bridges. Immunity 15:751-761

Tadokoro CE, Shakhar G, Shen S, Ding Y, Lino AC, Maraver A, Lafaille JJ, Dustin ML (2006) Regulatory T cells inhibit stable contacts between CD4+ T cells and dendritic cells in vivo. J Exp Med 203:505-511

Victoratos P, Lagnel J, Tzima S, Alimzhanov MB, Rajewsky K, Pasparakis M, Kollias G (2006) FDC-specific functions of p55TNFR and IKK2 in the development of FDC networks and of antibody responses. Immunity 24:65-77

Waibler Z, Sender L, Merten C, Hartig R, Kliche S, Gunzer M, Reichardt P, Kalinke U, Schraven B (2008) Signaling signatures and functional properties of anti-human CD28 superagonistic antibodies. PLoS One 3:e1708

Wallace DJ, Zum Alten Borgloh SM, Astori S, Yang Y, Bausen M, Kugler S, Palmer AE, Tsien RY, Sprengel R, Kerr JN, Denk W, Hasan MT (2008) Single-spike detection in vitro and in vivo with a genetic $\mathrm{Ca}(2+)$ sensor. Nat Methods 5:797-804

Wengner AM, Pitchford SC, Furze RC, Rankin SM (2008) The coordinated action of G-CSF and ELR + CXC chemokines in neutrophil mobilization during acute inflammation. Blood 111:42-49

van Zandbergen G, Solbach W, Laskay T (2007) Apoptosis driven infection. Autoimmunity 40:349-352

Zoumi A, Yeh A, Tromberg BJ (2002) Imaging cells and extracellular matrix in vivo by using second-harmonic generation and twophoton excited fluorescence. Proc Natl Acad Sci USA 99:1101411019 